\title{
Race, Class, and Community in a Southern Forest-Dependent Region
}

\author{
CHRIS R. COLOCOUSIS AND LUKE T. ROGERS
}

A cross rural America, many communities rely on manufacturing industries as their economic base. In 2004, the U.S. Department of Agriculture (USDA) classified 29 percent of nonmetropolitan counties as "manufacturing dependent." These industries-from forest products to automobiles-have supported a robust middle class in many rural places. However, a reliance on manufacturing can also mean a lack of economic diversification, which can in turn bring prolonged outmigration of youth as well as increased vulnerability to restructuring in the industries on which communities depend. In some places, these vulnerabilities exist alongside deep racial inequalities, persistent

\section{Key Findings}

In September and October 2007, Carsey Institute researchers surveyed 1,108 residents of southwestern Alabama about their own lives and perspectives on community issues. Key findings include the following:

- Despite similar rates of intergenerational social mobility between African Americans and whites, African Americans in the "Black Belt" of Alabama are disproportionately poor and employed in lower-skill jobs.

- African Americans were less likely than whites to say that residents in their communities trust one another, neighbors help one another out, or to report membership in local organizations.

- Both African American and white residents are tied to the region primarily by non-economic aspects of place, such as proximity to family, quality of life, and natural beauty. poverty, low educational attainment, and weak civic culture.

Through the Community and Environment in Rural America (CERA) initiative, Carsey Institute researchers have conducted surveys in selected regions across the United States. The goal is to learn how a broad cross section of Americans view the social, economic, and environmental changes affecting their lives and rural communities. This report outlines trends and conditions in a region defined largely by two dynamics: persistent, historically based racial inequalities, and a high degree of dependence on forest-based manufacturing. Clarke, Choctaw, Marengo, and Wilcox counties form part of Alabama's "Black Belt," a broad swath of the South with a heavily African American population, which extends east from Arkansas and Louisiana north to Virginia. Here, where forest covers more than three-quarters of the land, ${ }^{1}$ pulp and paper is the primary forest-based industry. The industry grew in Alabama during the 1950s and 1960s partly as a result of aggressive government recruitment, although the primary drivers of industrial expansion were the state's wood and water supply, low labor costs, transportation systems, and innovations in pulp making technology that allowed paper to be made from the state's abundant pines. ${ }^{2}$ Today the region owes what economic vitality it has to pulp and paper, yet it is highly disadvantaged and has not diversified its economy beyond a heavy reliance on manufacturing, the public sector, and low-wage service industries.

\section{The Region in Historical Context}

Contemporary conditions in this part of Alabama cannot be understood without a look at the region's historical development. Since colonization, the fertile soil has been used to grow a variety of crops, including cotton, which was established by the early 1800 s as the most important cash crop. Although agriculture was the backbone of the region through the nineteenth century, the cotton fields gradually 
gave way to forestland. Over the past century, the landscape has changed from primarily agricultural to one increasingly dominated by monoculture pine plantations; over onefourth of Alabama's forest area is comprised of plantations. ${ }^{3}$ Ownership of Alabama forestland is dominated by private entities, and through the 1980s, ownership was increasingly consolidated among fewer owners, particularly in the vicinity of pulp and paper mills. ${ }^{4}$ Importantly, ownership of forestland is dominated by whites; very little forestland across the state is owned by African Americans. ${ }^{5}$

Today all four counties are classified as manufacturingdependent by the USDA. ${ }^{6}$ In 2000 , more than one-half of manufacturing workers were employed in the wood products and paper industries. ${ }^{7}$ Each county has at least one pulp or paper mill within its borders, and several sawmills are located in the region. The manufacturing sector has been in decline, falling from 36 to 18 percent of all jobs in the region between 1970 and 2007. Nevertheless, manufacturing remains critical to the region's economic well-being. It accounted for 37 percent of the total compensation of employees in 2007, pointing to relatively high wages in the sector. ${ }^{8}$ The region is extremely rural, with much of the area comprised of very small settlements and unincorporated places. The largest communities in the region are Demopolis (population 7,400), Jackson $(5,100)$, and Thomasville $(4,500)$. The region is also losing its population, having decreased roughly 7 percent since 1990 .

Since 2007, researchers at the Carsey Institute of the University of New Hampshire have been investigating these types of changes through the CERA initiative. The CERA research team is conducting surveys and analyzing socioeconomic and environmental trends to better understand common patterns across rural America. A key goal of this effort is to provide decision makers and community organi-

Figure 1. AnNual household InCOME, By RACE

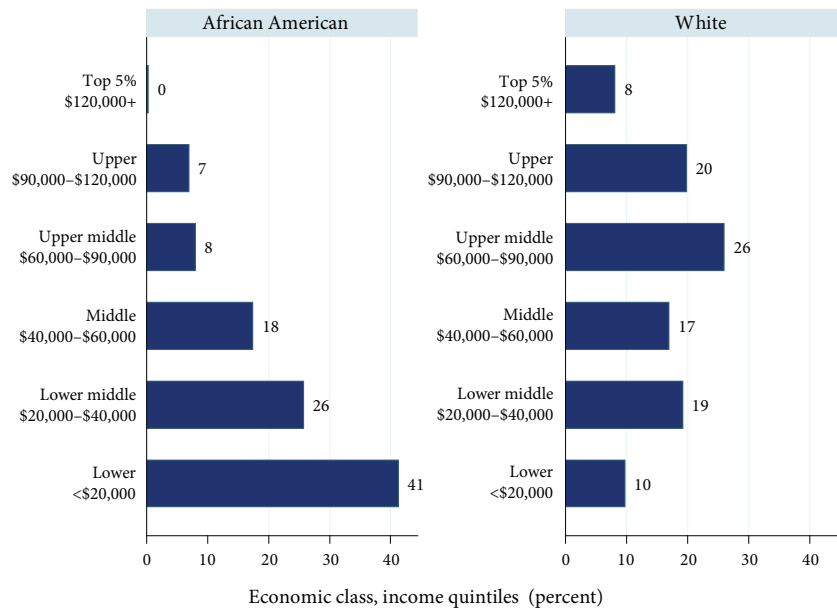

zations with information that can assist in promoting social and environmental resilience. CERA's initial stages in 2007 and 2008 included random sample telephone surveys with 8,800 residents in twenty-four rural counties in ten states across America. To learn more about how residents of this particular region view their communities, the Carsey Institute conducted telephone interviews with 1,108 adults during the fall of 2007. ${ }^{9}$ Researchers collected data on residents' experiences of change, their levels of concern about environmental issues, and the issues they see as most important in their communities.

\section{African Americans are Disproportionately Poor and More Often Work in Lower-Skilled Jobs}

The legacy of a plantation economy and reliance on slave labor can be seen in the region's socioeconomic and demographic conditions today. The population of Wilcox County was 72 percent African American in 2008, while Clarke, Choctaw, and Marengo counties ranged between 44 and 52 percent African American. The region has a much higher percentage of African Americans than the both the nation and state (12 percent nationally and 27 percent in Alabama). The USDA Economic Research Service classifies all four counties as persistently poor with low employment. ${ }^{10}$ Approximately one-fourth of the population had incomes below the poverty line in 2007, compared with 17 percent in the state. Race and class overlay these statistics. In 1999, 43 percent of African Americans were below the poverty line, while only 10 percent of non-Hispanic whites were.

The results of the survey underscore the region's historic racial inequalities. African American respondents (74 percent), for example, were less likely to own their own home than white respondents (91 percent) and reported substantially lower home values than whites. Whites also had much higher levels of educational attainment. Nearly twice as many African American (61 percent) than white (32 percent) respondents had only high school diploma or less. Similarly, 37 percent of white respondents reported having a college degree compared with 16 percent of African Americans. In part, these disparities persist because of state policy. The generous tax abatements used to recruit pulp and paper companies in the mid-twentieth century have had adverse effects on public education funding in rural Alabama, and the historically underfunded public school system is a primary obstacle to development in the region today. ${ }^{11}$

Figure 1 displays survey data that show the dramatically different household income distribution for African Americans and non-Hispanic whites, the two predominant 
racial groups in the area. Thirty-eight percent of African American respondents reported annual household incomes below $\$ 20,000$, compared with just 10 percent of whites. A relatively robust white middle class exists in the region, with 43 percent of whites reporting incomes between $\$ 40,000$ and $\$ 90,000$. By contrast, the African American middle class is much smaller. Racial divisions at the top are even more striking, with 28 percent of white respondents reporting household incomes greater than $\$ 90,000$ compared with just 7 percent of African Americans.

These differences in household income stem largely from employment circumstances. At the time of the survey, 21 percent of working-age African American respondents were unemployed, compared with just 4 percent of whites. Twenty-two percent of employed African American respondents worked in manufacturing, compared with 12 percent of whites. However, racial differences with respect to occupation are more pronounced and more consequential for the distribution of economic resources in the region. Among respondents employed in manufacturing, 90 percent of African Americans were in production occupations compared to 48 percent of whites. At the other end of the occupational spectrum, 16 percent of white respondents worked in management positions, while zero African American respondents did. These findings are consistent with earlier work, which called attention to racially segmented labor markets in the region's pulp and paper industry. ${ }^{12}$

Even beyond the manufacturing sector, African American respondents worked disproportionately in lower-level occupations, including production (21 percent of African Americans versus 7 percent of white respondents), personal care and service (10 percent versus 3 percent), food preparation and serving ( 7 percent versus 1 percent), and building and grounds cleaning and maintenance (6 percent versus less than 1 percent). African Americans are also scarce in higherlevel occupations, including management, business, and financial operations (2 percent versus 23 percent of whites), and office and administrative support occupations (1 percent versus 10 percent). Although African Americans have made significant inroads into manufacturing jobs where they were once excluded, given the hardships of most recent economic recession and the ongoing contraction of manufacturing in the region, such historical progress may today put them at higher risk of job loss.

Figure 2 displays the occupations of respondents' fathers, which provide a look back at the past structure of the regional economy and place contemporary patterns of racial inequality into historical perspective. ${ }^{13}$ Immediately evident is the degree to which work in the region was in the past dominated by relatively low-skilled occupations. The largest group worked in unskilled manual occupations, with skilled manual occupations following. As Figure 3 reveals, the
FIgURE 2. OCCUPATIONS OF RESPONDENTS' FATHERS

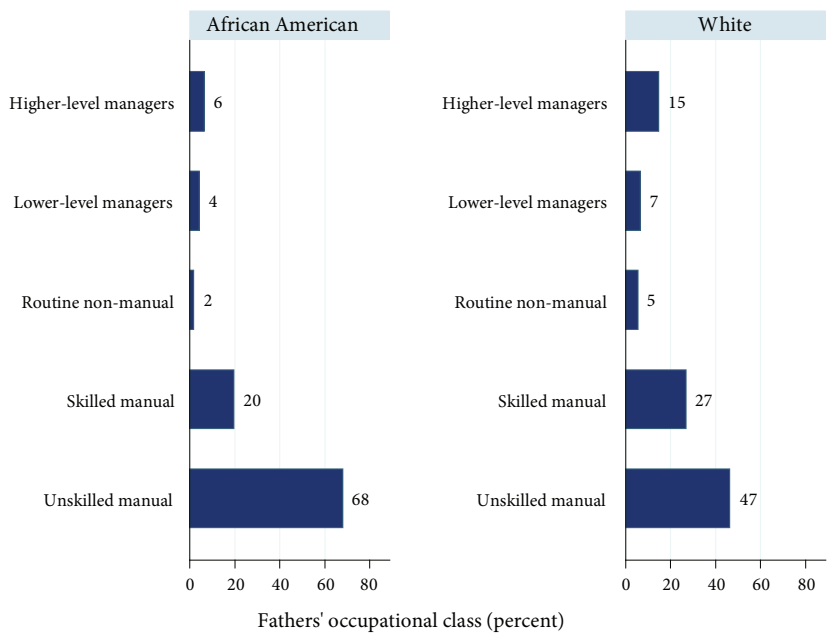

workforce (as of 2007) is far less dominated by low-skilled work. Together these figures form a picture of the agriculture-to-manufacturing-to-services transition that continues to unfold in the region.

Also evident in these figures is a striking pattern of racial inequality. Far more African Americans than whites had fathers who worked in unskilled manual jobs, and correspondingly fewer African Americans had fathers who worked in skilled manual or management positions. As Figure 3 shows, a greater percentage of both groups work in higher-class occupations than their fathers did, but racial differences persist. For example, at the highest and lowest ends of the occupational spectrum, African Americans are under- and overrepresented, respectively, by a margin of roughly two to one (see Figure 3).

Figure 3. OCCUPATION OF RESPONDENTS IN 2007

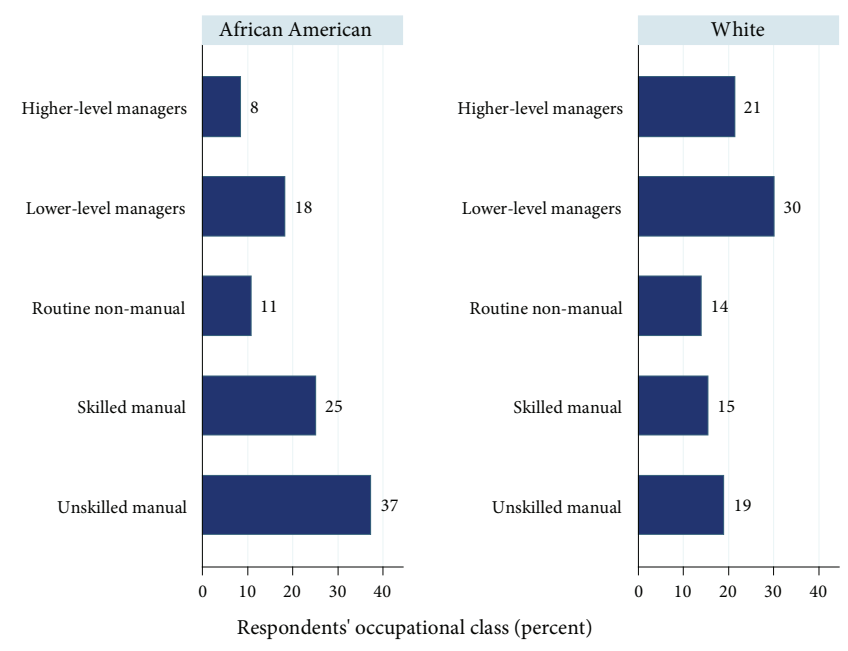


Using these data on respondents' and their fathers' occupations, it is possible to examine the extent of intergenerational social mobility in the region. Promisingly, the data show a general trend of upward social mobility for both groups. Fifty percent of respondents experienced upward mobility, reporting occupations that place them in a higher social class than their fathers. Thirty-two percent of respondents were in the same social class as their father, while 18 percent had experienced downward mobility. Patterns of intergenerational mobility were almost identical for African Americans and whites. Further, the two groups were extremely similar in the degree of upward or downward mobility they had experienced (for example, how far up or down the class ladder they moved). These trends in mobility largely represent wholesale shifts in the regional economy, with low-status occupations (such as farm laborers) being replaced by higher-status ones (sales positions). But given the dramatically different starting points of African American and white respondents, parity in rates of social mobility does not mean that racial equality exists in the region.

\section{Economic Conditions are Tough across the Region}

Although jobs have shifted to slightly higher-skilled positions over time, economic circumstances are difficult across the region. However, in 2007, respondents in Choctaw and Wilcox counties were roughly twice as likely as those in Clarke or Marengo counties to report having lost a job for economic reasons in the previous seven years. ${ }^{14}$ These high rates of recent job loss are linked to changes in the forest products industry similar to those unfolding in other forested rural areas. ${ }^{15}$ Another indicator of economic hardship is public assistance receipt. As Figure 4 shows, food stamps

Figure 4. ReCEnt Job LOSS AND PUblic AsSistanCE RECEIPT, BY COUNTY

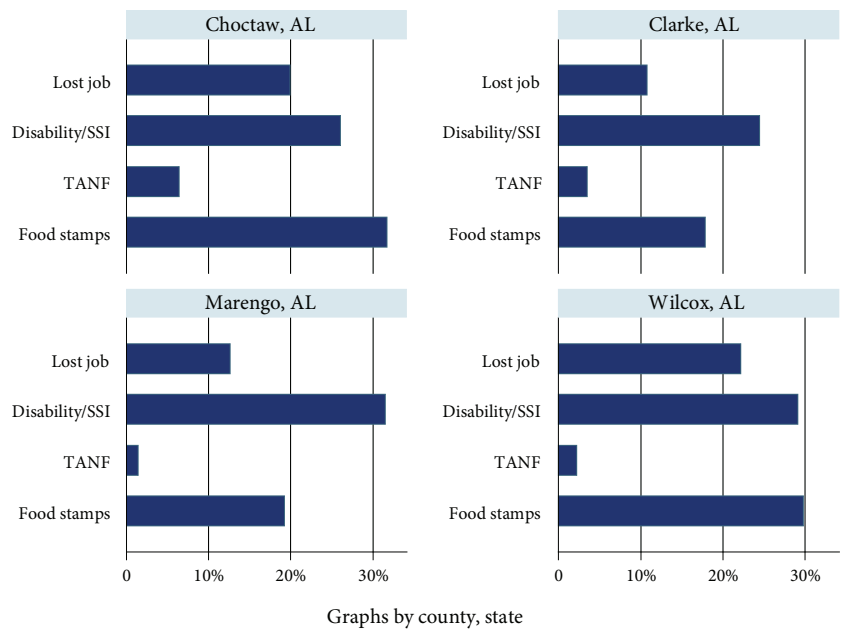

and disability insurance or supplemental security income are the most common types of aid received by respondents. Choctaw and Wilcox counties, where job losses were highest, had substantially higher levels of reported food stamp receipt than the other two study counties. Although African Americans were more likely than whites to report having received food stamps in the past two years (35 percent to 12 percent), there were no differences between these groups in disability/Social Security or Temporary Assistance for Needy Families receipt.

Making ends meet through a single job can be difficult in many rural areas, and the survey data reflect this reality. Twenty-two percent of employed respondents reported working a second job, a figure comparable to that in other persistently poor places. ${ }^{16}$ An equal percentage of African Americans and whites reported having second jobs. We also asked respondents whether they had done any of several other forms of work outside the formal economy. Overall, 40 percent of respondents indicated that they had done at least one form of extra work in the previous year. Household or auto repair and yard work or landscaping were the most common activities, followed by babysitting or other personal care, and raising animals or produce.

\section{Community Issues, Community Attachment, and Civic Culture}

The community impacts of recent job losses are evident as well. A Georgia Pacific paper mill in the town of Pennington is Choctaw County's largest employer, with about 1,000 workers. Since 2005, the mill has laid off several hundred employees. ${ }^{17}$ Not surprisingly, nearly four in ten Choctaw county residents saw the recent loss of forest-based jobs as having major community impacts. Throughout the rest of the region, 25 percent of respondents saw the loss of forestbased jobs as having major effects on their communities. Of course, the full impacts of the most recent recession are not captured in the survey data presented here; the region has seen several rounds of layoffs and mill closures since 2007.

Not surprisingly, a lack of job opportunities was the most commonly cited issue in the region, with 81 percent of respondents perceiving it to be a problem (see Figure 5). Illegal drug manufacturing and sales was the second most prominent local issue, with 67 percent of respondents reporting it to be a community problem. Poor school quality, a lack of health or social services, a lack of recreational opportunities, population decline, and lack of affordable housing were also seen as problems by sizable percentages. Despite their very different economic circumstances, African Americans and whites differed little on the extent to which they viewed poverty as a problem in their community. 
Figure 5. PERCEIVED COMMUNITY PROBLEMS

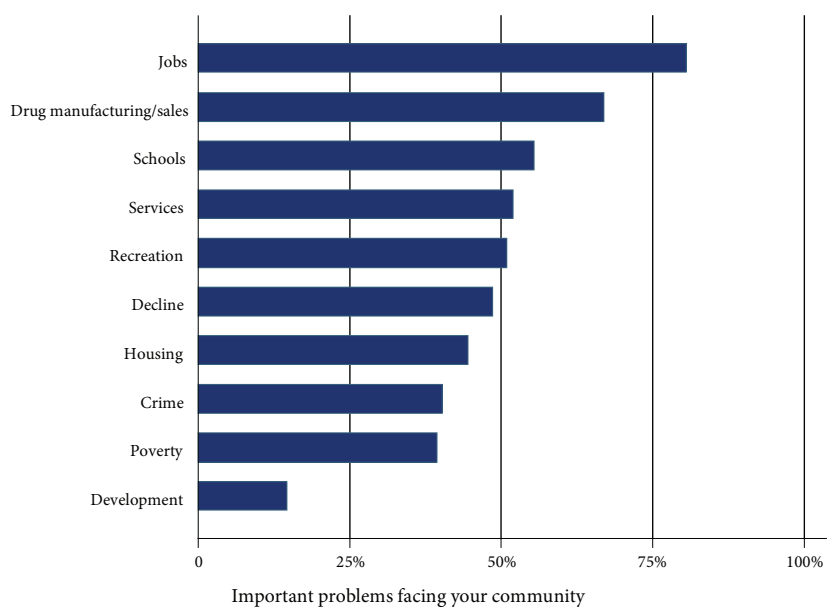

Despite these community issues, residents are relatively deep-rooted. Two-thirds of respondents said they expected to still be living in the area in five years. More African Americans ( 37 percent) than whites ( 28 percent) intended to leave the area over the next five years, which perhaps reflects the former group's disadvantaged status in the region. As Figure 6 shows, proximity to family and quality of life were respondents' two most important considerations in decisions to stay. The natural beauty of the area and (to a slightly lesser extent) recreational opportunities were second on the list. Local job, housing, and education opportunities-all of which are closely related to economic prospects-weighed less heavily in respondents' decisions to stay. Thus, it appears that residents are attached to their communities primarily because of noneconomic aspects of life-although attach-

Figure 6. CONSIDERATIONS IN DECISION TO REMAIN IN AREA

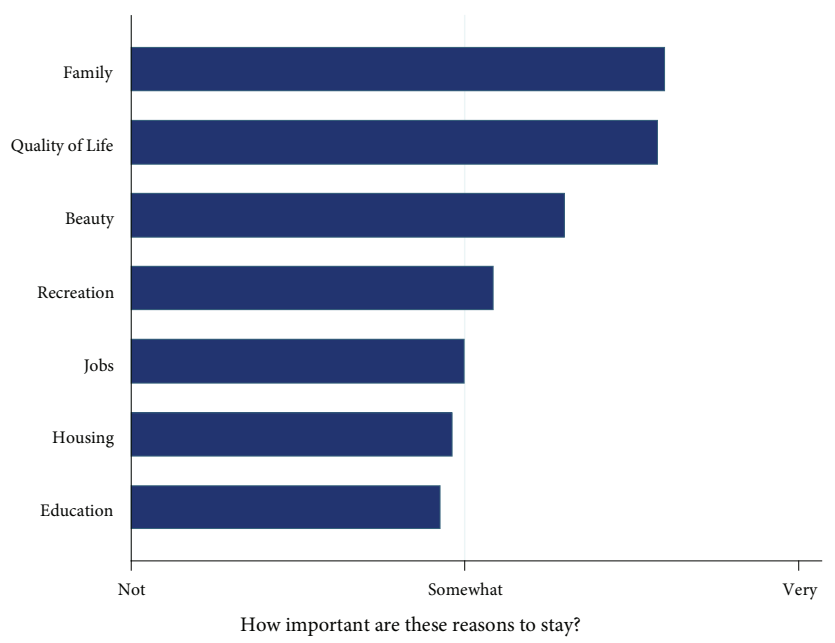

ment to place does not equate to satisfaction with life there. Given the extent of economic disadvantage in the region, many residents are actually stuck in place due to what can be substantial costs of relocation. While most residents said that they intended to stay, across the region a majority of respondents ( 72 percent) reported that, if asked, they would advise teenagers to leave the area for opportunities elsewhere. This trend is in line with that seen in other rural areas, ${ }^{18}$ and it likely reflects a combination of both a recognition of limited opportunities locally and a cultural expectation that young people will leave and broaden their horizons-perhaps before returning home one day.

Figure 7. Perceived trust and social cohesion, Civic ENGAGEMENT, BY RACE

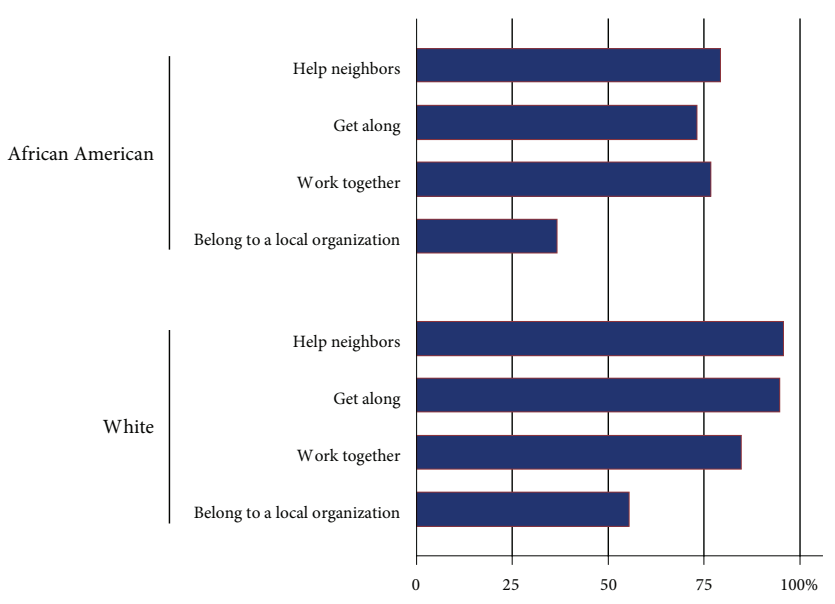

Trust, social cohesion, and civic engagement

Levels of trust, social cohesion, and civic engagement form another important dimension of community life-civic culture. A majority of residents agreed that trust and social cohesion in their communities was strong. However, more whites than African Americans said that people in their community are willing to help their neighbors and generally trust one another and get along, as shown in Figure 7. Differences were a bit less pronounced, although still significant, in the percentage of African Americans and whites reporting that people could work together effectively to address local issues. ${ }^{19}$ Levels of civic engagement, indicated here by membership in any civic, business, government, or other local organization, also varied significantly by race. Among African Americans, 37 percent reported membership in a local organization, while 56 percent of whites did. ${ }^{20}$ Together, the findings indicate not only less civic engagement than in several other non-chronically poor rural regions but also a pronounced racial division in the extent to which residents are engaged with local institutions. ${ }^{21}$ 


\section{The Future}

Finally, we wanted to gain a sense of where residents saw their communities heading. We first asked respondents for their perspectives on the future use of natural resources, a topic of particular relevance in this forest-dependent region. Forty-four percent of respondents said that natural resources should be conserved for future generations rather than used for job creation. However, 36 percent said that resources should be used to create jobs. Far fewer, only 19 percent of respondents, saw these two priorities as equal. Perhaps unsurprisingly given their firsthand experiences of economic disadvantage, more low income (47 percent) than middleor upper-income respondents said that resources should be used for job creation.

We also asked respondents whether they think their community will be a worse place to live, a better place, or about the same in ten years. A little more than half thought their community would be about the same. Thirty-two percent of respondents saw their community becoming a better place to live, while only 13 percent saw their community growing worse as a place to live in ten years. Perspectives on the future varied significantly by race. Despite their disadvantaged position in many areas of social and economic life, African Americans were more optimistic (39 percent) than whites (28 percent) about the future of their communities. These opinions were gauged in 2007, and it is possible that perceptions of the future are much different today after the profound economic disruptions underfoot. For example, the unemployment rate in Wilcox County stood at a remarkable 27 percent in February 2010, almost triple its mid-2007 level. ${ }^{22}$

\section{Conclusion}

When the forest products industry expanded in the region during the 1950s and 1960s, it was thought that industrial development would bring about real economic development. Instead, poverty and inequality have endured. ${ }^{23}$ The survey data presented here paint a picture of these communities as closely tied to the region's forest resource and marked by pronounced economic disadvantage and considerable racial inequality. In this region, where control of the resource base is dominated by whites, African Americans and whites inhabit different economic worlds. Our survey data contain no information on land ownership, but the racial inequalities outlined here must be understood in the context of historically rooted racial differences in control of the land. Land ownership represents a primary source of not only income but also wealth and is thus tied to issues of power that simultaneously underpin economic inequalities. ${ }^{24}$

In the presence of these divisions and a generally depressed economic climate, residents are tied to place primarily by non-economic aspects of their communities-family, the landscape, and general quality of life. While extraction of forest resources accounts largely for the degree of economic well-being that exists in the region, residents also appear to be engaged with non-economic resources afforded by the forest. Perspectives on the future of resource use reflect this dual, and sometimes conflicting, connection between communities and natural resources. While substantial expansion into high-wage service sector work or even tourism and recreation is unlikely in the Black Belt, hope for real economic development lies in the ability of the region to capitalize on the value of the forest in new and more equitable ways.

\section{Data}

The survey was administered by telephone to adults (18 years and older) in Choctaw, Clarke, Marengo, and Wilcox counties by the University of New Hampshire Survey Center in September and October of 2007, using random digit dialing. The total number of interviews in each of these counties was 301, 295, 249, and 263, respectively. Sixty-eight percent of respondents were female. Sixty-one percent were age 50 years of age or older. Of the respondents, 68 percent were non-Hispanic white and 29 percent were African American, with other categories composing 3 percent of the sample. Data were weighted to correct for potential sampling biases on the basis of age, sex, or race/ethnicity by deriving weights from an age/sex/race population profile of the region based on 2006 Census Bureau population estimates data (a maximum weighting factor was established to avoid unusual cases unduly influencing overall figures). The maximum margin of error (95 percent $\mathrm{CI}$ ) for percentages reported at the regional level was $+/-3$ percentage points. At the county level, it is +/5.6 percentage points. Reported between-group differences are statistically significant at the .05 level.

\section{A Note on Occupational Classification}

To assess intergenerational mobility, we use occupation as an indicator of individual-level socioeconomic position. Respondents' and their fathers' occupations were coded according to the Standard Occupation Classification-derived Census 2000 occupational codes and then transformed into International Standard Classification of Occupation 1988 (ISCO88) codes. ISCO88 codes were then assigned to an eleven category occupation-based class scheme. ${ }^{25}$ However, we did not use data on self-employment because they were not collected for respondents' fathers. Therefore, classes were determined based solely on occupation. The remaining nine class categories (minus self-employment) were then collapsed to create the five class categories. ${ }^{26}$ 


\section{Endnotes}

1. Analyses were done by Barb Cook and Joel Hartter in the Department of Geography at the University of New Hampshire. The satellite images capture the majority of land area in the four counties but do not correspond exactly to county boundaries.

2. Mahendra L. Joshi et al., "Investing in Industry, Underinvesting in Human Capital: Forest-Based Rural Development in Alabama," Society \& Natural Resources, 13 (2000): 291-319.

3. Alabama Forestry Commission, Forest Resource Report 2003, (Montgomery, AL: Alabama Forestry Commission, 2003); Andrew J. Hartsell and Tony G. Johnson, Alabama's Forests, 2005, U.S. Department of Agriculture Forest Service Southern Research Station Resource Bulletin SRS-146 (Washington, D.C., U.S. Department of Agriculture, 2005).

4. John C. Bliss, Mary L. Sisock, and Thomas W. Birch, "Ownership Matters: Forestland Concentration in Rural Alabama," Society \& Natural Resources, 11(4) (1998):401-410.

5. U.S. Forest Service National Woodlands Ownership Survey data.

6. In manufacturing-dependent counties, 25 percent or more of average annual labor and proprietors' earnings were from manufacturing during 1998 to 2000.

\section{U.S. Census 2000 STF4 Table PCT05.}

8. U.S. Bureau of Economic Analysis, Regional Economic Accounts, Local Area Personal Income Tables CA05 and CA25.

9. The four counties were selected on the basis of a number of criteria, including geographical location, extent of forest cover and private ownership, degree of reliance on manufacturing and presence of the forest products industry, population, and our desire for internal heterogeneity with respect to community conditions.

10. Persistently poor counties had individual poverty rates of 20 percent or greater in each decennial census from 1970 to 2000. In low-employment counties, fewer than 65 percent of residents between age 21 and 64 were employed in 2000 . In low-education counties, at least 25 percent of residents between age 25 and 64 lacked a high school diploma or GED, http://www.ers.usda.gov/Briefing/rurality/Typology/.

11. Mahendra L. Joshi et al., "Investing in Industry, Underinvesting in Human Capital: Forest-Based Rural Development in Alabama," Society \& Natural Resources 13 (2000): 291-319.

12. See Conner Bailey et al., "Segmented Labor Markets in Alabama's Pulp and Paper Industry," Rural Sociology, 61(3) (1996): 475-496.
13. Mothers' occupation is also an important factor in class mobility. However, for the sake of simplicity we restrict the analysis here to fathers' occupation only. See the note on occupational classification in Emily Beller, "Bringing Intergenerational Social Mobility Research into the Twentyfirst Century: Why Mothers Matter," American Sociological Review, 74 (2009): 507-528.

14. Questions were asked as follows: During the last seven calendar years, did you lose a job or leave one because your plant or company closed or moved, your position or shift was abolished, insufficient work, or some other similar reason? Have you received any income from disability insurance or SSI within the past two years? Have you received any from TANF (Temporary Assistance for Needy Families) within the past two years? Have you received food stamps within the past two years?

15. See Chris Colocousis, "The State of Coos County: Local Perspectives on Community and Change," Issue Brief No. 7 (Durham, NH: Carsey Institute, University of New Hampshire, 2007).

16. See Lawrence C. Hamilton et al., Place Matters: Challenges and Opportunities in Four Rural Americas, A Carsey Institute Report on Rural America, (Durham, NH: Carsey Institute, University of New Hampshire, 2008).

17. Jeff Amy, "Georgia-Pacific Laying off 30," [Mobile, AL] Press-Register, August 8, 2008.

18. Lawrence C. Hamilton et al., Place Matters: Challenges and Opportunities in Four Rural Americas, A Carsey Institute Report on Rural America, (Durham, NH: Carsey Institute, University of New Hampshire, 2008).

19. Perspectives on trust and cohesion also varied by social class and levels of perceived trust and cohesion increased with household income. However, racial differences persisted even when controlling for social class. Interestingly, racial differences in levels of trust were most pronounced among middle-income $(\$ 40,000-\$ 60,000)$ residents. Middle-income African Americans had the lowest percentage (63 percent) of any racial or income group agreeing with the statement about residents trusting one another.

20. However, most of the apparent effect of race on civic engagement is due to income differences. For both racial groups, as income increases, rates of membership steadily increase. However, low-income African Americans (26 percent) were less likely than low-income whites (41 percent) to belong to a local organization.

21. Lawrence C. Hamilton et al., Place Matters: Challenges and Opportunities in Four Rural Americas, A Carsey Institute Report on Rural America, (Durham, NH: Carsey Institute, University of New Hampshire, 2008). 
22. U.S. Bureau of Labor Statistics, Local Area Unemployment Statistics.

23. John C. Bliss and Conner Bailey, "Pulp, Paper, and Poverty: Forest-Based Rural Development in Alabama, 1950-2000," in Communities and Forests: Where People Meet the Land, Robert Lee and Don Field, eds. (Corvallis, OR: Oregon State University Press, 2000); Mahendra L. Joshi et al., "Investing in Industry, Underinvesting in Human Capital: Forest-Based Rural Development in Alabama," Society \& Natural Resources 13 (2000): 291-319.

24. See Jess Gilbert, Gwen Sharp, and M. Sindy Felin,"The Loss and Persistence of Black-Owned Farms and Farmland: A Review of the Research Literature and its Implications," Southern Rural Sociology 18(2) (2002): 1-30.

25. These were outlined in Harry Ganzeboom and Donald Treiman, "Internationally Comparable Measures of Occupational Status for the 1988 International Standard Classification," Social Science Research, 25 (1996): 201-309.

26. The class categories correspond to those outlined by Ganzeboom and Treiman as follows: "Higher service" consists of Group 1, "Lower service" consists of Group 2, "Routine clerical/sales" consists of Groups 3 and 11, "Skilled manual" consists of Groups 7 and 8, "Unskilled manual" consists of Groups 9 and 10.

\section{Authors}

Chris R. Colocousis is a research associate at the Carsey Institute and a doctoral candidate in the Department of Sociology at the University of New Hampshire (chris. colocousis@unh.edu).

Luke T. Rogers is a doctoral student in the Department of Sociology at the University of New Hampshire (ltp5@unh.edu).

\section{ACKNOWLEDGMENTS}

The authors would like to thank Larry Hamilton for his work on this project, and Conner Bailey, Janice Dyer, Jess Gilbert, and Curt Grimm for their thoughtful comments on earlier drafts.

\section{A UNIVERSITY Ali of NEW HAMPSHIRE}

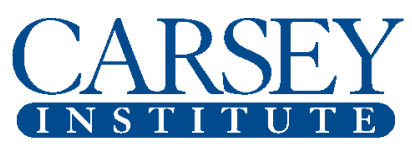

Building knowledge for families and communities

The Carsey Institute conducts policy research on vulnerable children, youth, and families and on sustainable community development. We give policy makers and practitioners timely, independent resources to effect change in their communities.

This work was supported by the Ford, W. K. Kellogg, and the Mary Reynolds Babcock Foundations.

Huddleston Hall

73 Main Street

Durham, NH 03824

(603) $862-2821$

www.carseyinstitute.unh.edu 